\title{
Determinação de dados experimentais de equilíbrio líquido-líquido para sistemas contendo éster metílico de ácidos graxos, glicerina bruta e metanol
}

\author{
D. de BASTIANI ${ }^{1}$, G. G. TIROLLO ${ }^{1}$, A. P. SILVA ${ }^{1}$, M. LANZA ${ }^{1}$ \\ ${ }^{1}$ Departamento de Engenharia Química e Engenharia de Alimentos. Centro Tecnológico. \\ Universidade Federal de Santa Catarina. EQA/CTC/UFSC, Florianópolis - SC, Brasil. \\ E-mail para contato: mlanza@enq.ufsc.br
}

\begin{abstract}
RESUMO - Estudos de equilíbrio líquido-líquido são fundamentais para predizer dados de equilíbrio termodinâmico e assim auxiliar na otimização das operações que envolvem produção e purificação de substâncias. Neste estudo, dados de equilíbrio líquido-líquido foram determinados para compostos envolvidos na produção de ésteres metílicos. Sistemas contendo glicerina bruta, ésteres metílicos e metanol nas temperaturas de 30,45 e $60{ }^{\circ} \mathrm{C}$ foram analisados. As massas dos componentes presentes nas fases formadas após o equilíbrio foram quantificadas por métodos analíticos, e assim, foi possível determinar diagramas ternários de equilíbrio para os sistemas estudados. Os diagramas tiveram boa representatividade e foi possível verificar a influencia da água e das impurezas presentes no sistema, oriundas da glicerina bruta.
\end{abstract}

\section{INTRODUÇÃO}

A previsão de esgotamento do petróleo tem incentivado a busca por fontes alternativas e renováveis de energia, o que incentivou a inserção do Biodiesel na matriz energética brasileira e despertou um grande interesse na comunidade cientifica (Ranganathan et al., 2008). O biodiesel é definido como acil-ésteres de ácidos graxos produzidos pela reação de transesterificação alcoólica de óleos e gorduras, empregando catalisadores homogêneos (hidróxidos alcalinos ou ácidos) ou catalisadores heterogêneos (metais, enzimas e zeólitas) (Pousa et al., 2007). A glicerina, coproduto da reação de transesterificação, possui muitas impurezas (ácidos graxos, catalisadores), sendo assim denominada de glicerina bruta. Com o aumento previsto da produção de biodiesel, o excedente de glicerina bruta também aumentará e sua inserção no mercado depende do seu grau de purificação (Pinto et al., 2005). Na produção e purificação do biodiesel e da glicerina bruta, ocorre a formação de fases líquidas com diferentes composições de reagentes e/ou produtos da reação. A termodinâmica tem papel fundamental na predição de sistemas que formam fases líquidas com diferentes composições e através de diagramas de equilíbrio de fases pode predizer o comportamento das substâncias envolvidas em um sistema em equilíbrio líquido-líquido.

\section{MATERIAIS E MÉTODOS}

Os compostos utilizados neste trabalho receberam a seguinte notação: (1) biodiesel metílico (97\% de pureza); (2) glicerina bruta (>80\% de pureza); (3) metanol (composto puro); 
(4) ésteres metílicos (composto puro); (5) glicerol livre (composto puro); (6) água (composto puro); (7) voláteis (metanol + água); (8) impurezas do biodiesel metílico; (9) impurezas da glicerina bruta. A tabela 1 apresenta a pureza dos compostos utilizados na geração dos pontos de mistura.

Tabela 1 - Proveniência e grau de pureza dos compostos envolvidos neste trabalho.

\begin{tabular}{lll}
\hline Nomenclatura & Proveniência & Pureza mínima em fração mássica $(w)$ \\
\hline Metanol & Vetec & 0,9980 \\
Biodiesel metílico & BS Bios $^{\mathrm{a}}$ & $0,9700^{\mathrm{b}}$ \\
Glicerina bruta & BS Bios $^{\mathrm{a}}$ & $0,8227^{\mathrm{c}}$ \\
\hline
\end{tabular}

${ }^{a}$ Gentilmente cedidos pela empresa BS Bios, Marialva/PR; ${ }^{\mathrm{b}}$ pureza referente a quantidade de ésteres metílicos; ${ }^{\mathrm{c}}$ glicerina bruta apresenta glicerol livre $(82,27 \%)$, água $(11,41 \%)$ e impurezas $(6,32 \%)$ em sua composição.

Experimento de equilíbrio líquido-líquido: $\mathrm{O}$ procedimento consistiu em adicionar massas pré-definidas, determinadas através do ponto de mistura que compreende a região bifásica, de biodiesel (1), glicerina bruta (2) e metanol (3) nas células de equilíbrio (que possuíam barras magnéticas em seu interior). É importante destacar que em todos os experimentos foram adicionados apenas biodiesel metílico (1), glicerina bruta (2) e metanol (3) para geração dos pontos de mistura. As células eram fechadas e conectadas a um banho com circulação constante (Micro Química MQBMP-01) e esse era ajustado à temperatura estudada. Inicialmente, as células foram agitadas com agitador magnético por 20 minutos e após esse período o agitador foi desligado e as células permaneciam conectadas ao banho termostático por 24 horas. As amostras das fases formadas após o equilíbrio, fase éster e fase glicerinosa, foram retiradas pelos septos das células com auxílio de seringas. As composições das fases foram analisadas conforme descrito abaixo.

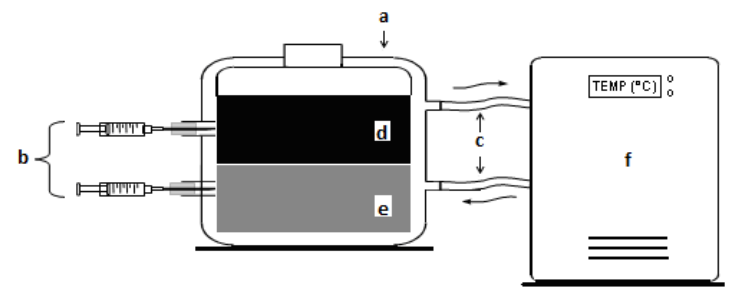

Figura 1 - Diagrama esquemático da célula de equilíbrio conectada ao banho termostático. a: célula; b: retirada de amostra das fases c: circulação de água; d: fase éster (FE); e: fase glicerinosa (FG); f: banho termostático. Fonte: Lanza (2008).

Determinação da fração de glicerol livre: O método utilizado para determinação de glicerol livre foi descrito por Cocks e Van Rede (1966). O método consiste na reação do glicerol com o periodato de sódio $\left(\mathrm{NaIO}_{4}\right)$ em solução aquosa ácida para produzir formaldeído e ácido fórmico, este último é utilizado para determinar a quantidade de glicerol através de titulação com $\mathrm{NaOH}(0,125 \mathrm{~N})$. A quantidade de glicerol livre contida na amostra foi determinada pela seguinte equação:

Glicerol livre $\left(w_{5}\right)=\left[\frac{9,209 \cdot N \cdot\left(V_{1}-V_{2}\right)}{m_{a}}\right] / 100$

Onde: $w_{5}$ é a fração mássica de glicerol livre,

$N$ é a normalidade da solução de $\mathrm{NaOH}$, 
$V_{l}$ é o volume da solução de $\mathrm{NaOH}$ gasto na amostra $(\mathrm{mL})$,

$V_{2}$ é o volume da solução de $\mathrm{NaOH}$ gasto no branco $(\mathrm{mL})$,

$m_{a}$ é a massa de amostra utilizada $(\mathrm{g})$.

Determinação da fração de água: A glicerina bruta apresenta água de lavagem em sua composição e ao adicionar essa glicerina ao sistema, ambas às fases após o equilíbrio podem apresentar um significativo teor de água. Para determinar a água presente nas fases do sistema foi utilizado o método Karl Fischer. No procedimento foi utilizado um equipamento de titulação semiautomático, marca Quimis e solução Karl Fischer Combi Tritant 5 da Apura.

As análises foram realizadas em triplicata para cada fase. O volume de reagente Karl Fischer gasto na titulação da amostra foi então utilizado nos cálculos para o teor de umidade segundo a equação 2 , onde o fator de correção foi previamente calculado.

$$
\operatorname{Agua}\left(w_{6}\right)=\left(\frac{V \cdot F}{10 \cdot m}\right) / 100
$$

Onde: $w_{6}$ é a fração mássica de água,

$F$ é o fator de correção,

$m$ é a massa da amostra (g),

$V$ é o volume da solução Karl Fischer gasto (mL).

Determinação da fração de metanol: A fração mássica de voláteis foi determinada através de gravimetria em estufa com circulação de ar a $60{ }^{\circ} \mathrm{C}$ por um período de 24 horas. $\mathrm{Na}$ evaporação as massas iniciais e finais da gravimetria referem-se aos voláteis total $\left(w_{7}\right)$, metanol e água, calculado pela Equação 3. Já a determinação do metanol foi dada pela Equação 4, sendo a fração de água $\left(w_{6}\right)$ determinada previamente pelo método Karl Fischer.

$$
\begin{aligned}
& \operatorname{Voláteis}\left(w_{7}\right)=\frac{\left(m_{\text {inicial }}-m_{\text {final }}\right)}{m_{\text {inicial }}} \\
& \operatorname{Metanol}\left(w_{3}\right)=\operatorname{Voláteis}\left(w_{7}\right)-\text { Água }\left(w_{6}\right)
\end{aligned}
$$

Onde: $w_{7}$ é a fração mássica de voláteis $\left(w_{7}=w_{3}+w_{6}\right)$;

$m_{\text {inicial }}$ e $m_{\text {final }}$ são as massas inicial e final da amostra (g), respectivamente;

$w_{3}$ é a fração mássica de metanol;

Determinação da fração de ésteres metílicos: A fração mássica de ésteres metílicos puros $\left(w_{4}\right)$ das fases éster e glicerinosa pode ser determinada por diferença através do balanço de massa. A Equação 5 fornece a fração mássica de ésteres metílicos puros.

$$
\text { Ésteres metílicos }\left(w_{4}\right)=1-w_{5}-w_{7}-w_{8}-w_{9}
$$

Onde: $w_{4}$ é a fração mássica de ésteres metílicos puros das fases em equilíbrio;

$w_{8}$ é a fração mássica de impureza do biodiesel metílico;

$w_{9}$ é a fração mássica de impureza da glicerina bruta; 
No entanto, as frações $w_{8}$ (impureza do biodiesel metílico) e $w_{9}$ (impureza da glicerina bruta) não puderam ser determinadas neste trabalho por limitações analíticas, visto que estas impurezas contêm diversas substâncias provenientes da reação do biodiesel e é difícil definir quais são estas substâncias o que as tornam impossíveis de serem quantificadas. Portanto, como a fração de ésteres metílicos $\left(w_{4}\right)$ é calculada pela diferença no balanço de massa, o termo $\left(w_{4}\right)$ deveria representar o valor real de éster metílico puro contido nas fases, mas na verdade representa a soma entre o valor real de éster metílico contido nas fases e as impurezas não quantificadas do biodiesel metílico e da glicerina bruta. Este valor pode ser representado conforme as equações 6 e 7 :

$$
\begin{aligned}
& w_{1^{\prime}}=1-w_{5}-w_{7} \\
& w_{1^{\prime}}=w_{4}+w_{8}+w_{9}
\end{aligned}
$$

Onde: $w_{1^{\prime}}$ é a fração mássica de ésteres metílicos somada as impurezas do biodiesel metílico e da glicerina bruta encontrada nas fases em equilíbrio (esse termo será chamado de "biodiesel residual", cuja notação para sua fração mássica será $w_{1^{\prime}}$ ).

Elaboração dos diagramas e desvio do balanço de massa das fases: Os diagramas de fases foram elaborados com o auxílio do software Origin 6.1. Para avaliar os desvios no balanço de massa das fases foi empregado o procedimento desenvolvido por Marcilla et al. (1995). Conhecendo os desvios do balanço de massa foi possível avaliar a qualidade dos dados experimentais.

\section{RESULTADOS E DISCUSSÕES}

\subsection{Dados experimentais para o sistema contendo biodiesel metílico, glicerina bruta e metanol a $30{ }^{\circ} \mathrm{C}$}

Nos resultados obtidos para o sistema contendo biodiesel metílico, glicerina bruta e metanol a $30{ }^{\circ} \mathrm{C}$ (Tabela 2 e Figura 2), as frações de água presente tanto na fase éster (FE) quanto na fase glicerinosa (FG) aumentam com o aumento de glicerol livre, mostrando a interação do glicerol com a água (Kirk-Othemer, 2007).

Tabela 2 - Dados de equilíbrio líquido-líquido para o sistema pseudoternário contendo nos

\begin{tabular}{|c|c|c|c|c|c|c|c|c|c|c|c|}
\hline & \multirow{2}{*}{\multicolumn{3}{|c|}{$\begin{array}{l}\text { Ponto de mistura } \\
(\mathrm{PM})\end{array}$}} & \multicolumn{4}{|c|}{ Fase glicerinosa $(\mathrm{FG})$} & \multicolumn{4}{|c|}{ Fase éster (FE) } \\
\hline & & & & \multirow[b]{2}{*}{$100 w_{1}}$, & \multirow[b]{2}{*}{$100 w_{5}$} & \multicolumn{2}{|c|}{ Voláteis $\left(w_{7}\right)$} & \multirow[b]{2}{*}{$100 w_{1}}$, & \multirow[b]{2}{*}{$100 w_{5}$} & \multicolumn{2}{|c|}{ Voláteis $\left(w_{7}\right)$} \\
\hline & $100 w_{1}$ & $100 w_{2}$ & $100 w_{3}$ & & & $100 w_{3}$ & $100 w_{6}$ & & & $100 w_{3}$ & $100 w_{6}$ \\
\hline $\mathrm{P} 1$ & 38,78 & 45,32 & 15,96 & 4,48 & 71,50 & 13,41 & 10,62 & 95,39 & 0,56 & 3,85 & 0,20 \\
\hline $\mathrm{P} 2$ & 29,80 & 13,12 & 57,13 & 5,09 & 14,53 & 77,62 & 2,77 & 85,43 & 0,68 & 13,68 & 0,22 \\
\hline
\end{tabular}
pontos de mistura, biodiesel metílico (1) + glicerina bruta (2) + metanol $(3)$, a $(30 \pm 0,1){ }^{\circ} \mathrm{C}$.

$w_{1}$, é a fração mássica de ésteres metílicos somada as impurezas do biodiesel metílico e da glicerina bruta calculada pela eq. $6 ; w_{5}=$ glicerol livre; $w_{6}=$ água; $w_{7}=w_{3}+w_{6}$.

Os desvios no balanço de massa podem ser observados na Tabela 3, sendo maior para o ponto de mistura com menor quantidade de glicerol livre. Os desvios, em geral, foram 
relativamente baixos e dentro do esperado, pois testes de validação da análise do periodato foram realizados e apresentaram desvios que determinaram desvios na faixa de $0,12 \%$ até 4,07 \% nas análises, podendo o desvio no balanço estar associado a uma superestimativa na determinação de glicerol livre, pois a massa calculada foi maior que a massa adicionada. $\mathrm{O}$ maior desvio observado a $30{ }^{\circ} \mathrm{C}$ foi de $2,724 \%$, ficando dentro do desvio esperado.

Tabela 3 - Desvios no balanço de massa global das fases éster (FE) e glicerinosa (FG) para o sistema pseudoternário contendo nos pontos de mistura biodiesel metílico (1) + glicerina bruta (2) + metanol (3) a $(30 \pm 0,1){ }^{\circ} \mathrm{C}$.

\begin{tabular}{cccccc}
\hline & $\begin{array}{c}\text { Massa FG } \\
\text { calculada }(\mathrm{g})\end{array}$ & $\begin{array}{c}\text { Massa FE } \\
\text { calculada }(\mathrm{g})\end{array}$ & $\begin{array}{c}\text { Massa total } \\
\text { calculada }(\mathrm{g})\end{array}$ & $\begin{array}{c}\text { Massa total } \\
\text { adicionada }(\mathrm{g})\end{array}$ & Desvio relativo (\%) \\
\hline P1 & 29,852 & 49,743 & 79,595 & 79,274 & 0,405 \\
P2 & 21,080 & 45,448 & 66,528 & 68,391 & 2,724 \\
\hline
\end{tabular}

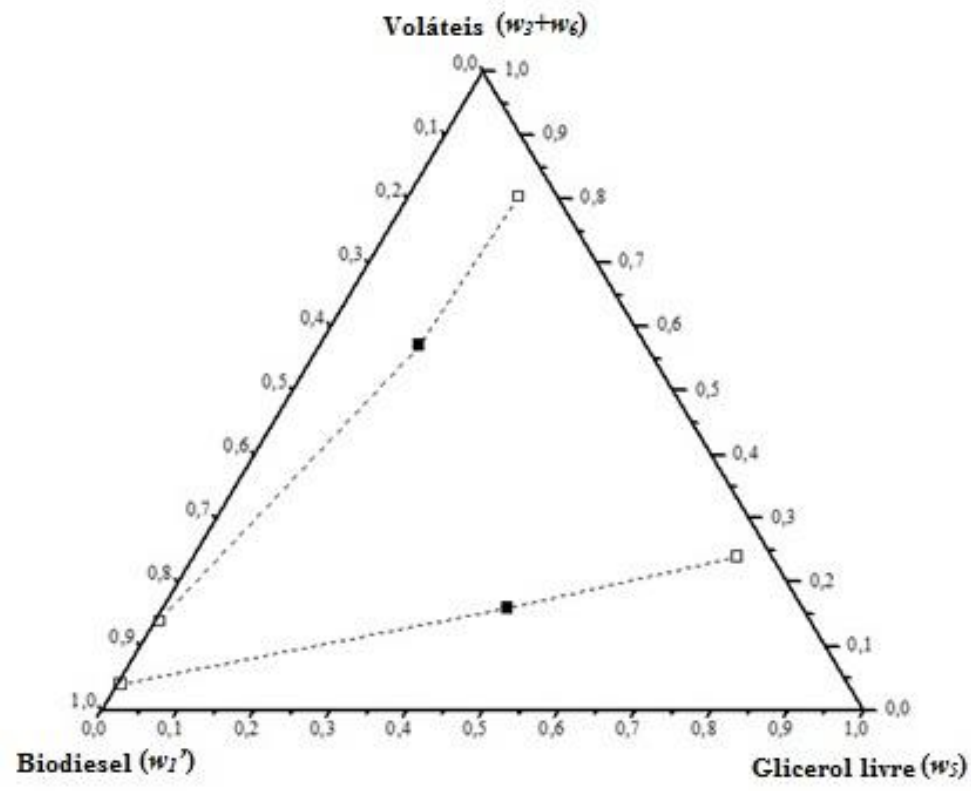

Figura 2 - Dados de equilíbrio líquido-líquido para o sistema pseudoternário contendo nos pontos de mistura biodiesel metílico (1) + glicerina bruta (2) + metanol (3) a $(30 \pm 0,1)^{\circ} \mathrm{C}$ : $\square$, FE e FG; $\mathbf{~ , ~ P M ; ~ - - - , ~ l i n h a s ~ e x p e r i m e n t a i s ~ d e ~ a m a r r a c ̧ a ̃ o . ~}$

\subsection{Dados experimentais para o sistema contendo biodiesel metílico, glicerina bruta e metanol a $45^{\circ} \mathrm{C}$}

Os resultados obtidos para o sistema contendo biodiesel metílico, glicerina bruta e metanol a $45{ }^{\circ} \mathrm{C}$ (Tabela 4 e Figura 3). O comportamento dos componentes das fases apresentam os mesmos perfis verificados a $30{ }^{\circ} \mathrm{C}$. As frações de água presente tanto na fase éster (FE) quanto na fase glicerinosa (FG) aumentam com o aumento de glicerol livre e a FG possui uma maior quantidade de água dissolvida. Analisando os desvios da Tabela 5, o maior desvio observado foi para o ponto de mistura com maior quantidade de glicerina. A glicerina possui impurezas e uma maior a quantidade dela no sistema sugere uma maior a quantidade 
de impurezas, podendo assim, o desvio estar associado a influencia dessas impurezas na determinação do glicerol, causando uma superestimativa das massas no sistema.

Tabela 4 - Dados de equilíbrio líquido-líquido para o sistema pseudoternário contendo nos pontos de mistura biodiesel metílico (1) + glicerina bruta (2) + metanol (3) a $(45 \pm 0,1){ }^{\circ} \mathrm{C}$.

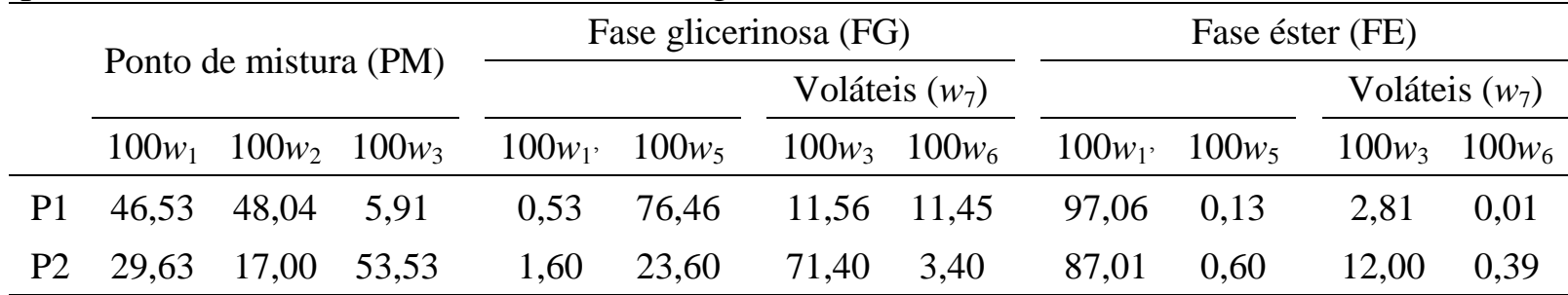

$w_{1}$, é a fração mássica de ésteres metílicos somada as impurezas do biodiesel metílico e da glicerina bruta calculada pela eq. $6 ; w_{5}=$ glicerol livre; $w_{6}=$ água; $w_{7}=w_{3}+w_{6}$.

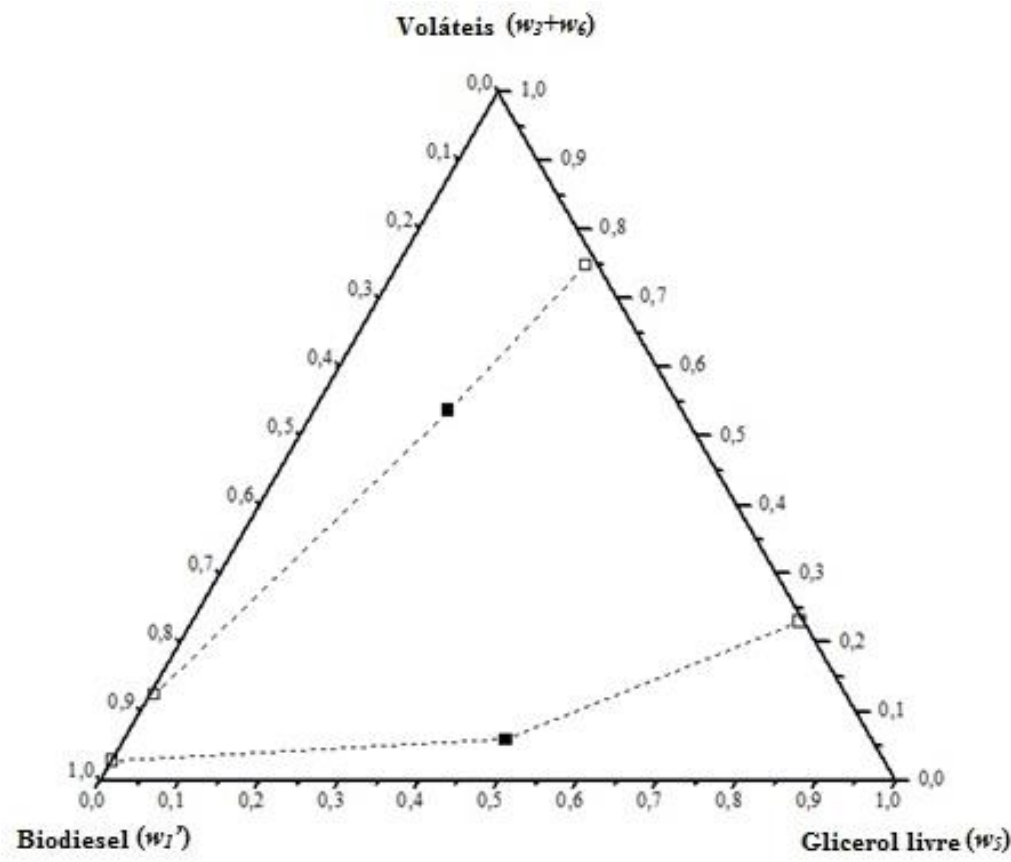

Figura 3 - Dados de equilíbrio líquido-líquido para o sistema pseudoternário contendo nos pontos de mistura biodiesel metílico (1) + glicerina bruta (2) + metanol (3) a $(45 \pm 0,1){ }^{\circ} \mathrm{C}: \square$, FE e FG; - PM; ---, linhas experimentais de amarração.

Tabela 5 - Desvios no balanço de massa global das fases éster (FE) e glicerinosa (FG) para o sistema contendo nos pontos de mistura biodiesel metílico (1) + glicerina bruta (2) + metanol (3) a $(45 \pm 0,1){ }^{\circ} \mathrm{C}$.

\begin{tabular}{cccccc}
\hline & $\begin{array}{c}\text { Massa FG } \\
\text { calculada }(\mathrm{g})\end{array}$ & $\begin{array}{c}\text { Massa FE } \\
\text { calculada }(\mathrm{g})\end{array}$ & $\begin{array}{c}\text { Massa total } \\
\text { calculada }(\mathrm{g})\end{array}$ & $\begin{array}{c}\text { Massa total } \\
\text { adicionada }(\mathrm{g})\end{array}$ & Desvio relativo (\%) \\
\hline P1 & 38,319 & 47,907 & 86,226 & 81,316 & 6,038 \\
P2 & 14,221 & 28,884 & 43,104 & 43,445 & 0,784 \\
\hline
\end{tabular}




\subsection{Dados experimentais para o sistema contendo biodiesel metílico, glicerina bruta e metanol a $60{ }^{\circ} \mathrm{C}$}

Nos resultados obtidos para o sistema contendo biodiesel metílico, glicerina bruta e metanol a $60{ }^{\circ} \mathrm{C}$ (Tabela 6 e Figura 4), o comportamento foi semelhante ao observado nas temperaturas de 30 e $45{ }^{\circ} \mathrm{C}$. O desvio observado na Tabela 7 foi maior para o ponto de mistura com uma maior quantidade de glicerina, assim como ocorre no sistema a $45^{\circ} \mathrm{C}$.

Tabela 6 - Dados de equilíbrio líquido-líquido para o sistema pseudoternário contendo nos pontos de mistura biodiesel metílico (1) + glicerina bruta (2) + metanol (3) a $(60 \pm 0,1){ }^{\circ} \mathrm{C}$.

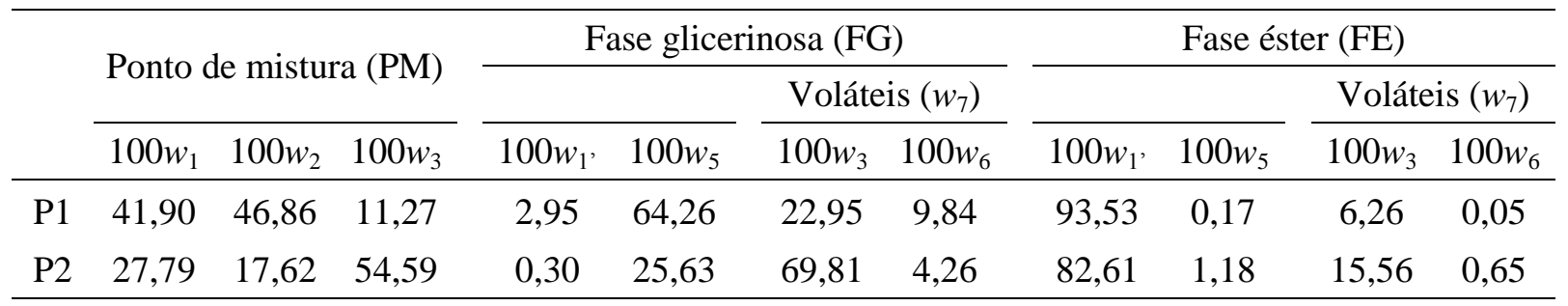

$w_{1}$, é a fração mássica de ésteres metílicos somada as impurezas do biodiesel metílico e da glicerina bruta calculada pela eq. $6 ; w_{5}=$ glicerol livre; $w_{6}=$ água; $w_{7}=w_{3}+w_{6}$.

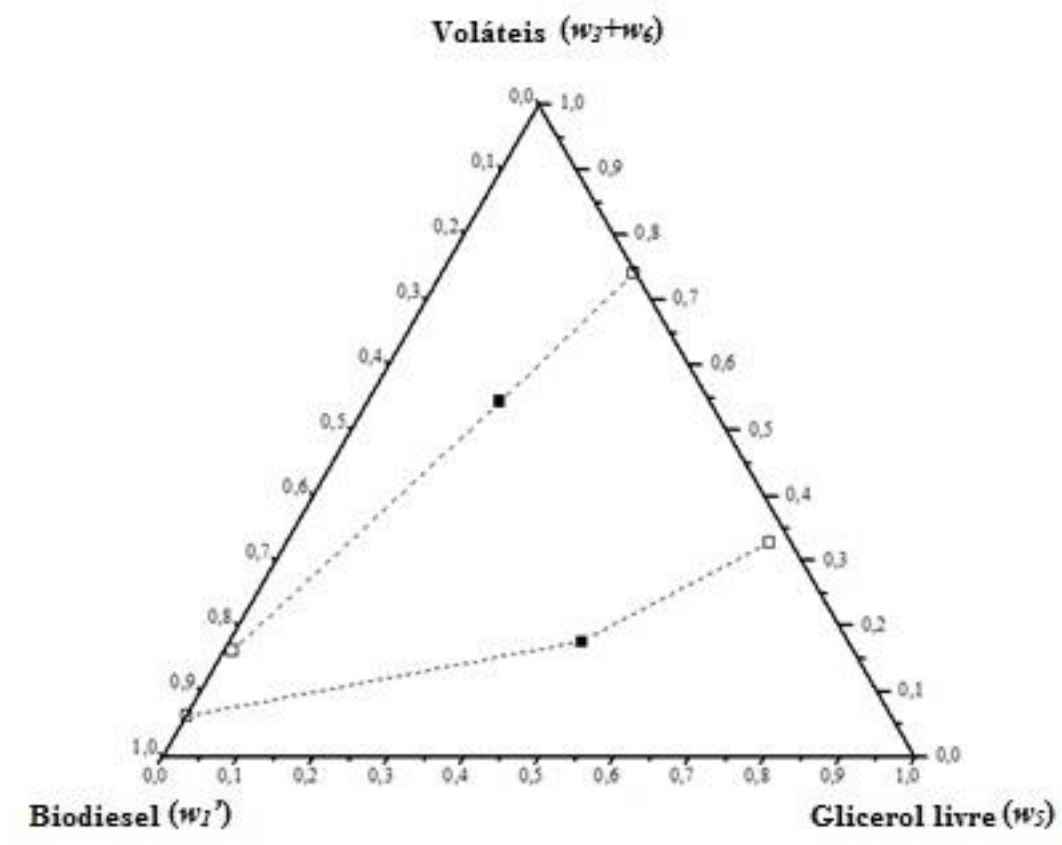

Figura 4 - Dados de equilíbrio líquido-líquido para o sistema pseudoternário contendo nos pontos de mistura biodiesel metílico (1) + glicerina bruta (2) + metanol (3) a $(60 \pm 0,1){ }^{\circ} \mathrm{C}: \square$, FE e FG; - PM; ---, linhas experimentais de amarração. 
Tabela 7 - Desvios no balanço de massa global das fases éster (FE) e glicerinosa (FG) para o sistema pseudoternário contendo nos pontos de mistura biodiesel metílico (1) + glicerina bruta (2) + metanol (3) a $(60 \pm 0,1){ }^{\circ} \mathrm{C}$.

\begin{tabular}{cccccc}
\hline & $\begin{array}{c}\text { Massa FG } \\
\text { calculada }(\mathrm{g})\end{array}$ & $\begin{array}{c}\text { Massa FE } \\
\text { calculada }(\mathrm{g})\end{array}$ & $\begin{array}{c}\text { Massa total } \\
\text { calculada }(\mathrm{g})\end{array}$ & $\begin{array}{c}\text { Massa total } \\
\text { adicionada }(\mathrm{g})\end{array}$ & Desvio relativo (\%) \\
\hline P1 & 33,594 & 50,660 & 84,2536 & 80,1176 & 5,1625 \\
P2 & 23,193 & 46,194 & 69,3872 & 69,4808 & 0,1348 \\
\hline
\end{tabular}

\section{CONCLUSÕES}

Os resultados apresentados neste trabalho demonstraram que métodos analíticos utilizados para determinar as composições da fase glicerinosa e da fase éster apresentaram um bom desempenho nas temperaturas de 30,45 e $60^{\circ} \mathrm{C}$. Nos resultados obtidos, a todas as temperaturas, as frações de água presente na fase glicerinosa (FG) aumentam com o aumento de glicerol livre, demonstrando a interação do glicerol com a água por serem ambos polares. Quanto maior a fração de glicerina no sistema, maior o teor de água identificado nas análises, porém, esse teor de água não esta associado ao desvio observado no balanço de massa. Para as temperaturas mais elevadas, 45 e $60^{\circ} \mathrm{C}$, o desvio no balanço de massa foi maior que o esperado, ficando o erro associado à determinação de glicerol livre.

\section{REFERENCIAS}

COCKS, L. V.; VAN REDE, C. Laboratory Handbook for Oil and Fat Analysis. Acad. Press, Londres, p. 404, 1966.

KIRK-OTHMER ENCYCLOPEDIA OF CHEMICAL TECHNOLOGY, 5nd Edition, Vol. 1, Anthony Standen, Editor. Interscience, New York, 2007.

LANZA, M.; BORGES NETO, W.; BATISTA, E.; POPPI, R. J.; MEIRELLES, A. J. A. Liquid-Liquid Equilibrium Data for Reactional Systems of Ethanolysis at 298.3 K. Journal of Chemical \& Engineering Data, 53, 5-15, 2008.

MARCILlA, A.; RUIZ, F.; GÁRCIA, A. N. Equilíbrio líquido-líquido de sistemas quaternários água-etanil-acetona e cloreto de sódio a $25{ }^{\circ} \mathrm{C}$. Fluid Phase Equilibria, 112, 73 289 (1995).

PINTO, A. C.; GUARIEIRO, L. L. N.; REZENDE, M. J. C.; RIBEIRO, N. M.; TORRES, E.A.; LOPES, W.A.; PEREIRA, P.A.P.; ANDRADE, J.B. Biodiesel: An Overview, Journal of Brazilian Chemical Society, 16, 1313-1330, 2005.

POUSA, G. P. A. G., SANTOS, A. L. F. e SUAREZ, P. A. Z. History and Policy of Biodiesel In Brazil. Energy Policy, 35, 5393-5398, 2007.

RANGANATHAN, S. V.; NARASIMHAN, S. L.; MUTHUKUMAR, K. An Overview of Enzymatic Production of Biodiesel. Bioresource Technology, 99, 3975-3981, 2008. 